Health and happiness

\section{Health, happiness, and higher levels of social organisation}

\section{Nancy Ross}

\section{Healthy communities tend to be happy communities}

le their paper Subramanian and colleagues show us that both individual and community level health and happiness tend to covary but that the community level health-happiness covariation is quite a bit stronger than that for individuals. ${ }^{1}$ Their approach is novel in that they examine the covariation in these two outcomes nested within individuals who are in turn nested within USA communities.

The study design of the Subramanian paper forces the questions: Are people naturally endowed with a degree of happiness that life events, whether positive or negative, are unlikely to influence? Or are there life circumstances, set in motion by social contexts, which have enduring effects on our levels of happiness? If we assume that people have a set point of happiness homoeostasis that only wavers slightly in response to either positive and negative life conditions and events we might expect that happy people will tend to feel healthy, be optimistic, vital, and we would expect health and happiness to covary within individuals across contexts. On the other hand, if it is life circumstances that permanently change our level of happiness then we would be more inclined to suggest that some underlying life conditions are implicated in the codetermination of health and happiness.

Easterlin argues that there indeed are some conditions of life, such as a decline in health status, that permanently change our level of happiness. Pointing to data from the US general social survey, he shows that across the life course, those in poorer health report consistently lower happiness than those in better health and he conjectures that the balance of evidence favours the direction of causality running from health to happiness and not the other way around. ${ }^{2}$ Marriage has a lasting positive effect on happiness and divorce a lasting negative effect. The case of income, however, is quite different. Although cross sectional studies like that of Subramanian and colleagues typically show a significant positive association between income and happiness even in the presence of control variables, he suggests that cohort studies show no trend of increased income being associated with increased happiness. So according to Easterlin's ideas, health and marriage can permanently affect happiness but, in psychologist's parlance, there seems to be "complete hedonic adaptation" for income. Income's inability to nudge us towards happiness, he explains, is attributable to the fact that material desires expand with increased incomes leaving us perpetually at roughly the same distance between our material goals and our ability to attain them.

There also seems to be some kind of hedonic adaptation at higher levels of social organisation. In the USA real personal incomes have grown substantially since the middle of the past century but the proportion of Americans reporting themselves "very happy" has hovered around one third. ${ }^{3}$ Internationally, happiness is not correlated with GDP per capita beyond a threshold of about $\$ 13000 .^{4}$ Indeed, there is a remarkably similar shape (diminishing returns to both health and happiness beyond a basic threshold) to the relation between income and health and income and happiness at the scale of the nation state-suggesting that income, health, and happiness covary strongly at higher levels of social organisation. This is precisely what Subramanian and colleagues report for US communities.

But why do we not see the same degree of alignment of health and happiness within individuals? Myers states emphatically that "age, gender and income (assuming people have enough to afford life's necessities) give little clue to someone's happiness" (page 65), although we know these to be strong predictors of an individual's health status through years of epidemiological study. ${ }^{3}$ Health, however measured, tends to decline with age. Women consistently outlive men in most countries around the world. Despite the modest role of health selection effects, the epidemiological evidence supporting the causal relation between income and health status is strong. Thus it would seem that some of the most important common indicators of health and happiness are probably still out there to be measured in a future study. Among other candidates, things like self esteem, extent and quality of social relationships, job satisfaction, and leisure time activities should probably be considered. ${ }^{35}$ As for the role of community context, we know from the Subramanian piece that healthy communities tend to be happy communities and this finding should force us to consider what forms of social organisation are most supportive of these candidate common indicators of health and happiness.

J Epidemiol Community Health 2005;59:614. doi: 10.1136/jech.2004.031732

Correspondence to: Dr N Ross, Department of Geography, McGill University, Montral, Quebec, Canada; nancy.ross@mcgill.ca

\section{REFERENCES}

1 Subramanian SV, Kim F, Kawachi I. Covariation in the socioeconomic determinants of self rated analysis of individuals and communities in the USA. J Epidemiol Community Health 2005:59:664-9.

2 Easterlin R. Explaining happiness. PNAS 2003;100: $11176-83$.

3 Myers DG. The funds, friends and faith of happy people. Am Psychol 2000;55:56-67.

4 Doyle R. Calculus of happiness: assessing well-being across societies. Sci Am 2002;280:32. 5 Deiner E. Subjective well-being: the science of happiness and a proposal for a national index. Am Psychol 2000;55:34-43. 
Nutrition

\section{Nutritional transition: a determinant of global health}

\section{Stephen J Genuis}

\section{Much of the world's disease burden results from faulty nutrition, which is a largely preventable risk factor. It is now time for a global diet strategy.}

$\mathrm{P}$ erhaps more than ever before in recorded history there is a huge gap between health as it could be and health as it really is. The management of patients with persistent affliction and unremitting pain increasingly dominates medical practice ${ }^{12}$ and it is apparent that individual and public dietary habits are an important determinant in the mounting load of chronic suffering and illness. ${ }^{3}$ Exorbitant rates of adult onset diabetes as well as an epidemic of paediatric and adult obesity have triggered a careful re-examination of national food guidelines and population dietary practices. In recognition of the health ramifications of faulty dietary intake, the World Health Organisation in May 2004 implemented a global diet strategy, ${ }^{3-5}$ a move branded as a "landmark achievement in global public health policy." ${ }^{\prime 5}$

Distinct challenges related to nutrition and health in developing countries, such as food shortage and inequitable distribution of resources, often result from political, economic, and social factors. Even within developed nations enjoying prosperity, cutting edge medical technology, and accessible health care, however, it is increasingly evident that rates of chronic illness are mounting, ${ }^{6-9}$ thus threatening the sustainability of health care systems in many jurisdictions. The Centers for Disease Control and other groups have provided substantial research data confirming that the rise in illness and chronic pain are, in part, attributable to nutritional choices. $^{3{ }^{10-12}}$ As early as 1988, the US Surgeon General's Report on Nutrition and Health concluded that illness related to modern dietary habits had risen so noticeably that faulty nutrition significantly contributed to most deaths in the USA. ${ }^{13}$

The integrity of the physical body is determined, to a great degree, by the quality of consumed nutrients that continually nourish and rebuild the human structure. Deficiencies of ordinary micronutrients can be associated with a range of illnesses such as prostate cancer, ${ }^{14}$ miscarriage, ${ }^{15}$ and stroke, ${ }^{16}$ as well as an array of paediatric afflictions including widespread behavioural and learning disorders, ${ }^{17}$ certain congenital abnormalities, ${ }^{18}$ and even such common ailments as ear infections. ${ }^{19}$ The Canadian Journal of Psychiatry, for example, recently highlighted various psychiatric challenges including anxiety, depression, and hyperactivity problems associated with insufficient levels of essential fatty acids. ${ }^{20}$ Primary reasons for micronutrient insufficiency include the following: food is commonly grown in soil that has become nutritionally deficient; microwaving and prolonged cooking at high temperatures diminishes nutritional value ${ }^{21} 22$; produce is commonly harvested in advance of vine ripening, the stage at which many basic nutrients develop; and toxins including various herbicides and pesticides may have an adverse effect on nutrients. Furthermore, fast food with its questionable nutritional status has become a dietary staple for many families. ${ }^{23}{ }^{24}$ As well as nutritional deficiency, exposures to potential toxins in foods are also a cause for concern.

Potentially toxic and allergenic agents in common foods are becoming more prevalent and, although much of the research on toxic effect remains at an early stage, there are increasing data that evoke concern. ${ }^{25}$ To expedite rapid and maximal growth, many farm animals destined for human consumption are injected with potent hormones including oestrogens, as well as being fed potentially toxic growth promoting feed additives. ${ }^{26-29}$ It is noteworthy that because of safety concerns, the European Union has steadfastly banned beef treated with growth hormones. ${ }^{28}$ In North America, dietary analysis by public agencies has showed that some ordinary foods consumed by many families now contain pesticide residue, antibiotics, heavy metals, industrial chemicals, and untested genetically engineered ingredients. ${ }^{26}{ }^{30-35}$ Routinely consumed synthetic additives, such as artificial colours, flavours, and preservatives may provoke untoward reactions and long term effects of eating irradiated food have not been adequately studied. Toxins in food are also an important concern in obstetrical care: just as drugs and alcohol can affect the developing fetus, recent warnings that caution pregnant women to limit consumption of seafood because of teratogenic contaminants ${ }^{36}$ give evidence of potential in utero impact of food toxins.

An accumulating body of evidence has pointed to hyperinsulinaemia resulting from dietary choices as an aetiological factor in the development of many chronic medical problems. ${ }^{37-39}$ Hypertension, dyslipidaemia, coronary artery disease, and type 2 diabetes are among the most common chronic conditions seen by family physicians in western cultures, yet remain rare in less westernised societies. For example, 50 million Americans are hypertensive, 10 million have type 2 diabetes, and 72 million adults have dyslipidaemia. ${ }^{38}$ Habitual consumption of high glycaemic food carbohydrates such as refined sugar and many common cereals promotes the development of insulin resistance and compensatory hyperinsulinaemia. ${ }^{38}$ Awareness of the impact of raised insulin concentrations resulting from dietary challenges is increasing; research has implicated this physiological change with other common conditions such as acne and hair loss, ${ }^{38}$ polycystic ovarian disease, ${ }^{40}$ pre-eclamptic toxaemia, ${ }^{41}$ as well as prostate, breast, and colon cancer. ${ }^{38} 4243$ As increased insulin concentrations also have a significant growth promoting hormone effect, higher fetal insulin concentrations in response to high glycaemic loads provided to the mother may be accounting for larger fetal growth. With high rates of cephalopelvic disproportion and associated caesarean section figures of $24 \%$ in the USA and $21 \%$ in Canada, ${ }^{44}{ }^{45}$ the issue of diet in pregnancy needs to be carefully considered. The myriad health sequelae associated with habitual high glycaemic consumption and mounting western type illness in developing nations adopting western dietary behaviours, explain the high glycaemic caution (in addition to the fruit and vegetable promotion) in the WHO "Global strategy on diet, physical activity and health."'3

While the medical discipline of nutrition is emerging as an area of primary health importance, this domain has not been a focus for medical training and continuing medical education. ${ }^{46}{ }^{47}$ It would be outlandish for a building contractor or architect to complete training in construction without an all embracing knowledge of structural 


\section{What this paper adds}

It is my desire that this commentary will bring attention to the contribution of nutritional factors to the escalating problem of chronic disease. Many people consider health and illness to be entirely independent of their own behaviour and voluntary choices, and regardless of unhealthy practices, perceive that health can be purchased in a medicine or vitamin bottle. Much of the general public now expects to consume medical services in much the same fashion that they consume fast food: rapid service, brief encounters, and immediate satisfication. As there is mounting evidence of the close relation between nutritional transition and disease, physicians need to be advocates for health promotion and prevention, in part, through dietary assessment and intervention.

materials, yet most physicians have received limited instruction about dietary nutrients, the building materials of the human frame. As a result, consideration of nutritional causation for medical problems occurs infrequently in everyday clinical practice ${ }^{48}$ and the underlying aetiology of various health difficulties is commonly unexplored.

Despite ample evidence confirming the need for good nutrition as a prerequisite for optimal health, ${ }^{10}$ dietary habits have changed substantially over the past few decades with accumulating research showing that many contemporary foods are nutritionally inadequate and that some contain potentially harmful substances. Study of "nutritional transition", ${ }^{25}$ the changing nature of food consumed by the average person, and its relation to human health, is an area of intense investigation that requires careful consideration when exploring the health status of individual patients as well as health trends within populations. With the realisation that much of the world's disease burden results from faulty nutrition, a largely preventable risk factor, the WHO has recently unveiled a global diet strategy, emphasising the inextricable relation between nutrition and human health.

J Epidemiol Community Health

2005;59:615-617.

doi: 10.1136/jech.2004.028985

Correspondence to: Dr S Genuis, 2935-66 Street, Edmonton, Alberta, Canada T6K $4 \mathrm{Cl}$; sgenuis@ualberta.ca

\section{REFERENCES}

1 Davis RM, Wagner EH, Groves T. Managing chronic disease. BMJ 1999;318:1090-1.

\section{Policy implications}

The recent World Health Assembly strategy to introduce a new dietary initiative is an important first step in the commitment to improve global nutritional practices. However, there is much literature to confirm that most physicians are not trained in nutrition and do not consider this important field when managing illness. This paper will hopefully contribute to increasing physician awareness and facilitate the introduction of policies and programmes to educate the public about the need for prevention and promotion of community health, in part, through diet.

2 The World Health Report 2002. Reducing risks, promoting healthy life. Geneva: World Health Organisation, 2002:3-167

3 World Health Assembly. Global strategy on diet, physical activity and health, WHA57.17. Geneva: World Health Organisation, 2004: 1-20

4 Phillips MW Jr. The WHO's global health strategy: a call to arms for dietetics professionals. J Am Diet Assoc 2004; 104:520-3.

5 Meek C. Global diet and exercise plan approved. CMAJ 2004;171:22

6 Murray CJL, Lopez AD, eds. The global burden of disease: a comprehensive assessment of mortality and disability from diseases, injuries, and risk factors in 1990 and projected to 2020. Boston, MA: Harvard University Press, 1996:4-990.

7 Wagner EH, Groves T. Care for chronic diseases. BMJ 2002;325:913-14.

8 Nettleton S. The sociology of health and illness. Cambridge: Polity Press, 1995:1-253.

9 Jones K, Moon G. Health, disease and society: an introduction to medical geography. London: Routledge, 1987: 12-376.

10 Centers for Disease Control and National Center for Chronic Disease Prevention and Health Promotion. Physical activity and good nutrition: essential elements to prevent chronic diseases and obesity 2003. Nutr Clin Care 2003:6:135-8.

11 How important are nutrition and dietary factors in health and chronic disease prevention? Nutr Clin Care 2003:6:143.

12 Vitamin D, cancer, and chronic pain. D deficiencies are problematic but avoidable. Health News 2004;10:12.

13 United States Public Health Service. Office of the Surgeon General. The Surgeon General's Report on Nutrition and Health. Public Health and Disease Prevention. Washington, DC: DHHS (PHS) publication no 88-50210, 1988: 1-750.

14 Rayman MP. The importance of selenium to human health. Lancet 2000;356:233-4.

15 George L, Mills JL, Johansson ALV, et al. Plasma folate levels and risk of spontaneous abortion. JAMA 2002;288:1867-3.

16 Knekt P, Kumpulainen J, Jarvinen R, et al. Flavinoid intake and risk of chronic diseases. Am J Clin Nutr 2002;76:560-8.

17 Stevens L, Zentall SS, Abate ML, et al. Omega-3 fatty acids in boys with behavior, learning and health problems. Physiol Behav 1996;59:915-20.

18 Czeizel AE, Dudas I. Prevention of the first occurrence of neural-tube defects by periconceptional vitamin supplementation. N Engl J Med 1992;327:1832-5.

19 Linday L, Dolitsky J, Shindledecker R, et al. Lemon-flavored cod liver oil and a multivitaminmineral supplement for the secondary prevention of otitis media in young children: pilot research. Ann Otol Rhinol Laryngol 2002;111:642-52.
20 Haag M. Essential fatty acids and the brain Can J Psychiatry 2003;48:195-203

21 Vallejo F, Garcia-Viguera C, Tomas-Barberan FA Phenolic sompound contents in edible parts of broccoli inflorescences after domestic cooking $J$ Sci Food Agric 2003;83:151 1-16.

22 Gil MI, Ferreres F, Tomas-Barberan FA. Effect of postharvest storage and processing on the antioxidant constituents (flavonoids and vitamin C) of fresh-cut spinach. J Agric Food Chem 1999;47:2213-17.

23 Schlosser E. Fast food nation. New York Houghton Mifflin, 2001:13-270.

24 Weisburger JH. Hazards of fast food. Environ Health Perspect 2004; 112:A336.

25 Glade MJ. Food, nutrition and the prevention of cancer: a global perspective. American Institute for Cancer Research/World Cancer Research Fund, American Institute for Cancer Research 1997. Nutrition 1999;15:523-6.

26 Canadian Food Inspection Agency. On pesticides, agricultural chemicals, veterinary drugs, environmental pollutants and other impurities in agri-food commodities of animal origin. Fiscal year 1998/1999. Canadian Food Inspection Agency Report 1999;1:1-61.

27 Rogan WJ, Ragan NB. Evidence of effects of environmental chemicals on the endocrine system in children. Pediatrics 2003;112:247-52.

28 Birchard K. European Union and USA hold firm over importing hormone-treated beef. Lancet 1999:353:1864.

29 Novilla MN. The veterinary importance of the toxic syndrome induced by ionopheres. Vet Hum Toxicol 1992;34:66-70.

30 Groth E, Benbrook CM, Lutz K. Do you know what you're eating? An analysis of U.S. government data on pesticide residues in foods. Public service projects department; technical division. Consumers Union of United States Report 1999:5-42.

31 Buechner P, Neufeld S, Mausberg B. Metallic lunch: an analysis of heavy metals in the Canadian diet. Environmental Defence Canada Report 2004:3-37.

32 Wiles R, Davies K, Campbell C. Overexposed: organophosphate insecticides in children's food. Environmental Working Group Report 1998:9-45.

33 Canadian Food Inspection Agency. On pesticides, agricultural chemicals, environmental pollutants and other impurities in agri-food commodities of plant origin. Fiscal year 2000/ 2001. Canadian Food Inspection Agency Report 2001;2:1-87.

34 Butler D, Reichhardt T. Long-term effect of GM crops serves up food for thought. Nature 1999;398:651-6.

35 Sehmer J. Mercury in seafood. CMAJ 2002:167:122-4.

36 Olsen SF. Mercury, PCB, and now eicosapentaenoic acid: still another reason why pregnant women should be concerned about eating seafood? Int J Epidemiol 2001;30:1279-80.

37 DeFronzo RA, Ferrannini E. Insulin resistance. A multifaceted syndrome responsible for NIDDM, obesity, hypertension, dyslipidemia, and atherosclerotic cardiovascular disease. Diabetes Care 1991;14:173-94.

38 Cordain L, Eades MR, Eades MD. Hyperinsulinemic diseases of civilization: more than just syndrome X. Comp Biochem Physiol A Mol Integr Physiol 2003; 136:95-112.

39 Reaven GM. Pathophysiology of insulin resistance in human disease. Physiol Rev 1995;75:473-86.

40 Falsetti L, Eleftheriou G. Hyperinsulinemia in the polycystic ovary syndrome: a clinical, endocrine and echographic study in 240 patients. Gynecol Endocrinol 1996; 10:319-26.

41 Fuh MM, Yin CS, Pei D, et al. Resistance to insulinmediated glucose uptake and hyperinsulinemia in women who had preeclampsia during pregnancy. Am J Hypertens 1995;8:768-71.

42 Bruning PF, Bonfrer JM, van Noord PA, et al Insulin resistance and breast-cancer risk. Int J Cancer 1992:52:511-16.

43 Giovannucci E. Insulin, insulin-like growth factors and colon cancer: a review of the evidence. J Nutr 2001;131:3109-20s. 
44 Stein R. Caesarean births hit high mark: a quarter of babies delivered surgically. Washington Post 2002:Dec 16:A01.

45 Bushe F. New thinking on C-sections: are they such a bad thing? Med Post 2003;39:1, 88 .
46 Mihalynuk TV, Scott CS, Coombs JB. Selfreported nutrition proficiency is positively correlated with the perceived quality of nutrition training of family physicians in Washington State. Am J Clin Nutr 2003;77:1330-6.
47 Lo C. Integrating nutrition as a theme throughout the medical school curriculum. Am J Clin Nutr 2000;72(suppl 3):882-9S.

48 Kopelman P, Lennard-Jones J. Nutrition and patients: a doctor's responsibility. Clin Med 2002;2:391-4. health impacts of non-healthcare policies and the lack of interest of most major journals in publishing public health research-are compounded in the UK by the Research Assessment Exercise that has led to a dearth (or death?) of academic public health posts and research. The third is the lack of studies of interventions to underpin modelling research. This is both the most important and would be the easiest to address, given political will and the accompanying funding.

What is needed to take forward this type of research? Firstly, good quality primary studies on the effects of change. ${ }^{5}$ Even where there is good evidence of a causal relation, reversibility cannot be assumed ${ }^{7}$ : as a quantified illustration, the magnitude of the effect of a rise or a fall in cigarette price on cigarette consumption (the elasticities) differ. ${ }^{8}$ In relation to socioeconomic inequalities, while cross sectional studies of unemployment and health are subject to direct and indirect selection effects, ${ }^{9}$ factory closure studies overcome this problem, ${ }^{10}$ but do not directly answer the question, "how much health gain would be expected from the creation of a certain number of jobs?"which arises frequently in the context of health impact assessment.

In the UK, the 2004 Wanless Report lamented the lack of evidence of cost effectiveness of interventions to improve population health. ${ }^{11}$ Where such evidence does exist, almost all focuses on individual level interventions, yet health impact assessments consider projects, programmes, or policies that affect whole populations or significant groups. Explaining the health effects of interventions requires a robust study design that is able to answer the question asked $^{12}$ but it does not require that the researchers initiate or implement the intervention whose effects are being examined. Wanless suggested that a useful design is to exploit opportunities of "natural experiments" there is good evidence of some income redistribution in the UK in the past seven years, but so far there seems to be no interest in assessing the health impact, even though it is likely to reflect well on the government. It remains to be seen whether the UK or other governments and funders of research will become interested in the type 
of research that Cole and others are pioneering.

$J$ Epidemiol Community Health 2005;59:617-618

doi: $10.1136 /$ jech. 2005.034355

\section{Authors' affiliations}

J Mindell, London Health Observatory, UK

$M$ Joffe, Department of Epidemiology and

Public Health, Imperial College London, UK

Correspondence to: Dr J Mindell, Department of Epidemiology and Public Health, University College London, 1-19 Torrington Place, London WCIE 6BT, UK

Funding: none.

Conflicts of interest: none declared.

\section{REFERENCES}

1 Cole BL, Shimkhada R, Morgenstern H, et al. Projected health impact of the Los Angeles City living wage ordinance. J Epidemiol Community Health 2005:59:645-50.

2 Backlund E, Sorlie PD, Johnson NJ. A comparison of the relationships of education and income with mortality: the national longitudinal mortality study. Soc Sci Med 1999:49:1373-84.

3 Morris JN, Donkin AJM, Wonderling D, et al. A minimum income for healthy living. J Epidemiol Community Health 2000:54:885-9.

4 Maslow A. "Higher" and "lower" needs. [Reprinted in Stacey C, DeMartino M, eds. Understanding human motivation. Cleveland: Howard Allen Publishers, 1958], J Psychol 1948:25:433-6

5 Joffe $M$, Mindell J. A framework for the evidence base to support health impact assessment. $J$ Epidemiol Community Health 2002:56:132-8.
6 Anderson RM, May RM. Infectious disease of humans: dynamics and control. Oxford: Oxford University Press, 1991.

7 Mindell J, Boaz AL, Joffe $M$, et al. Enhancing the evidence base for HIA. J Epidemiol Community Health 2004:58:546-51.

8 Andrews RL, Franke GR. The determinants of cigarette consumption: a meta-analysis. J Public Policy Market 1991;10:81-100.

9 Bartley M. Ferrie J, Montgomery SM. Living in a high-unemployment economy: understanding the health consequences. In: Marmot $M$, Wilkinson RG, eds. Social determinants of health. Oxford: Oxford University Press, 1999.

10 Keefe V, Reid P, Ormsby C, et al. Serious health events following involuntary job loss in New Zealand meat processing workers. Int J Epidemiol 2002;31:1155-61.

11 Wanless D. Securing good health for the whole population. London: HM Treasury, 2004.

12 Petticrew M, Roberts H. Evidence, hierarchies, and typologies: horses for courses. J Epidemiol Community Health 2003;57:527-9.

\section{Speaker's corner}

\section{The misuse of euphemisms in public health: the case of "food insecurity"}

W can assume that public health tends to suffer a kind of primordial tension between the individual and collective levels of organisation, which can manifest itself in different ways and demand distinct treatments. The issue is known to affect the risk of fallacies (aggregative or atomistic/ecological) when you attempt to study aspects pertaining to individuals or societies and moves back and forth between these levels of organisation. In this process, the terrible individual experience of hunger is overattenuated and "transformed" in collective terms into something comparatively harmless, referred to as "food insecurity".

It would be worthwhile to begin here with an argumentative exercise verging on the absurd by clarifying our position, even though risking the possibility of falling into sophistic rhetoric. In this sense, we draw an analogy between hunger and pain. Based on Michel Serres, ${ }^{1}$ one of the most striking events in the 20th century was the possibility of greater control over somatic pain through the development of powerful analgesics and anaesthetics widely used in modern medicine. How do you consider, in collective terms, the dimension of individual pain, a non-transferable human experience, proper to yourself?

The expression "analgesic insecurity" would certainly prove unsatisfactory and perhaps even absurd for such a purpose. Clearly, in various aspects, a person's relationship to food is not equivalent to that with anaesthetic and analgesic drugs. Humankind would not survive without food, and we do not even need expert middlemen to prescribe food. There is no "need", but in today's world there are clearly many nutritional experts who dictate the healthiest ways of eating in individual and collective terms, with a view towards health promotion.

In addition, in both Portuguese and Spanish, we have coexisting in the same expression ("segurança alimentar" or "seguridad alimentaria", respectively) something that fails to lexicalise a specificity in hunger problems. Meanwhile, in English we have "food security" to designate facets related to the precariousness involved in insufficiency or scarcity of food, whether in production, stability of distribution flows, and access. And we also have "food safety" to indicate aspects related to the precariousness involved in sufficiency (or excess) food in terms of quality and harmlessness (lack of contamination by micro-organisms or toxic metals). Even so, there is a certain famished element causing discomfort due to the outrage that is unduly attenuated by treating the hunger of multitudes of human beings as something impersonal under the cold technical designation "food insecurity".

Correspondence to: Dr Luis David Castiel, Fundação Oswaldo Cruz, Escola Nacional de Saúde Pública, Rua Paula Freitas 100/101, Copacabana, Rio de Janeiro, RJ, Brasil; luis.castiel@ensp.fiocruz.br

\section{REFERENCE}

1 Serres M. Hominescences. Paris: Le Pommier, 2001. 